\title{
Mathematics identity research: the state of the art and future directions
}

\section{Review and introduction to ZDM Special Issue on Identity in Mathematics Education}

\author{
Mellony Graven ${ }^{1}$ [ $\cdot$ Einat Heyd-Metzuyanim²
}

Accepted: 4 April 2019 / Published online: 13 April 2019

(c) The Author(s) 2019

\begin{abstract}
Identity research in mathematics education has become increasingly prominent over the past two decades. In the last few years, there have been several reviews of identity literature in the field of mathematics education generally, or specifically focused on mathematics learner identities or mathematics teacher identity. We begin our paper by summarizing the key findings of these reviews, pointing to various categorizations proposed by their authors, and the key critiques raised therein. We then report on our more recent review of identity literature in mathematics education published in the top twenty mathematics education journals over the past 5 years ( 47 articles in total). This review enables us firstly to speak descriptively about the extent to which the field is evolving (or not) in relation to earlier findings (dominant regions, focus of research, methods and perspectives used). Secondly, following deeper analysis of the papers, we speak to the way in which the field is addressing (or not) key critiques raised by reviews. Our analysis points to several theoretical, methodological and empirical absences and challenges requiring further engagement. We further highlight key absences in the research, particularly a lack of crossnational comparative studies and studies that connect learner and teacher identities. We then provide a summary discussion and analysis of the contributions of the present special issue papers and engage with how these take the field forward. Finally, we engage with the implications of our analysis and recommendations for future directions for research.
\end{abstract}

\section{Introduction}

Identity provides a powerful bridge between learning and cultural context (Sfard and Prusak 2005). In mathematics education, identity has been particularly useful in exploring why so many learners might disengage from mathematics without falling into cognitive deficit discourses. Identity research entered the field of mathematics education during what Lerman (2000) termed the social turn in mathematics education. Indeed, most of the identity literature in mathematics education draws on socio-cultural theories of learning (Heyd-Metzuyanim, Lutovac and Kaasila 2016) and aligns with a Meadian, identity-as-action view (Darragh 2016). Popular frameworks used include socio-linguistics;

Mellony Graven

m.graven@ru.ac.za

Rhodes University, Grahamstown, EC, South Africa

2 The Technion - Israel Institute of Technology, Haifa, Israel learning as participation; figured worlds and positioning theory; socio-political theories; cultural historical activity theory; critical race theory and commognitive theorydrawing on, for example, influential theorists such as Gee (2000); Wenger (1998); Holland, Lachicotte, Skinner and Cain (1998); Harré and van Langenhove (1999); and Sfard (2008) (Heyd-Metzuyanim, Lutovac and Kaasila 2016; Darragh 2016; Radovic, Black, Williams, Salas 2018).

The concept of identity has its origins in the work of Mead (1934) and Erikson (1968). For Mead identity was multiple (though appearing more unified to the individual), sometimes contradictory, and developing in interaction with the environment. For Erikson identity was more unified developing throughout one's life (Graven and Lerman, 2014). Darragh (2016, p. 26) notes two key views that cut across identity research, namely identity 'as an action or identity as an acquisition'. She relates these to Meadian and Eriksonian perspectives as follows:

Erikson understood identity as an acquisition, something that one has and that becomes coherent and consistent. A 
Meadian identity is an action, it is something one does, and it is multiple, contradictory and socially constituted. (Darragh 2016, p. 27).

At the most basic level, mathematics education identity research can be broadly split into two categories in terms of what the research focuses on: either learner identities (school or undergraduate mathematics learners) or teacher identities (pre- and in-service, specialised and non-specialised). We see this split emerging in recent reviews published on either mathematics learner identity (e.g. Radovic et al. 2018) or teacher identity (Lutovac and Kaasila 2017; Lutovac and Kaasila, 2018c) and in the most recent Springer Encyclopedia of Mathematics Education having separate entries for mathematics teacher identity and mathematics learner identity (Graven and Lerman, 2019; Darragh and Radovic, 2019a).

At a more complex level, identity research in mathematics education can be categorized according to various theoretical perspectives it uses (Darragh 2016) and/or the way in which identity definitions are established and operationalized (Radovic et al. 2018). These categorizations are discussed further in 2.2 below in respect to key contributions of recent reviews to developing conceptual coherence in the field.

\section{Common findings and issues identified in reviews on identity research in mathematics education}

In the past 3 years there have been several reviews on identity research in mathematics education in general (Darragh 2016; Langer-Osuna and Esmonde 2017; Heyd-Metzuyanim, Lutovac and Kaasila 2016), mathematics learner identity (Radovic et al. 2018) and mathematics teacher identity (Lutovac and Kaasila 2018a). We believe, these point to a 'coming of age' of the field as does this special issue. We begin by summarizing the common findings and critiques that these reviews point towards, so as to establish what currently seems well-known or established by those working in the field. These reviews tend to firstly provide a description of the field, often including descriptive statistics. Secondly, they critique the field particularly on issues of conceptual coherence. Finally, the systematic reviews of Darragh (2016) and Radovic et al. (2018) offer various categorizations of identity research that we believe contribute significantly to establishing greater conceptual clarity and coherence in the field. We discuss these contributions below.

\subsection{Descriptive results of the field from various reviews}

While the reviews by Langer-Osuna and Esmonde (2017) and Heyd-Metzuyanim, Lutovac and Kaasila (2016) provide commentary on the field of identity research in mathematics education generally, they did not conduct systematic reviews and thus do not provide descriptive statistics in the way Darragh (2016) does. Darragh's review from 1997 up to 2014 began around the start of identity research in mathematics education and included 188 articles across 85 journals. Below we summarise some key findings in relation to the distribution of research over time, across mathematics education journals and across regions. We do this not only to summarize what has been established, but also to provide a basis for comparison with our more recent review of research.

Darragh's (2016) review shows an increasing trend over time with less than 5 articles per annum published in the first 7 years (1997-2003) and more than 18 articles per annum in the last 5 years (2010-2014). In terms of the distribution of articles across regions, Darragh found the USA dominated (36\% of all articles), followed by the UK $(15 \%)$, Europe (11\%), Australia (10\%); New Zealand (10\%) and South Africa (5\%). Of the mathematics education research journals, where half (94) of the articles in Darragh's (2016) review were located, Educational Studies in Mathematics (ESM 18) and the Journal for Research in Mathematics Education (JRME 15) dominated followed by the Journal of Mathematics Teacher Education (JMTE 10); the journal Research in Mathematics Education (RME 10), and For the Learning of Mathematics (FLM 8). Darragh (2016) indicates an almost even split between articles focused on teacher (45\%) and learner identity (50\%), further indicating research on practicing teachers $(28 \%)$ being higher than that of pre-service teachers (17\%). She does not however provide further breakdown in terms of the level of teachers (e.g. primary or secondary) and does not provide any breakdown of research across levels of learners.

In terms of perspectives used in mathematics identity literature all reviews mentioned herein note that socio-cultural frames dominate in studies of learners' and teachers' identities. Darragh (2016) identified five categories of research based on different theoretical perspectives taken, namely participative, narrative, discursive, psychoanalytic and performative. She did not use these categories to provide statistics of the distribution of articles across these (possibly because of issues of overlap or lack of clarity on perspective used, see Sect. 2.2 below). Instead she provided descriptive statistics on the dominant theorists drawn on in the research, indicating that the greatest theoretical influence was that of Lave and Wenger (1991) and/or Wenger (1998) (41\% of the articles drew on these). This was followed by the work of Holland and colleagues (1998) (20\%) and Gee (2000) (18\%). She further notes commonly cited literature as that of Sfard and Prusak (2005) (cited by $21 \%$ of articles), Boaler and colleagues (e.g. Boaler and Greeno 2000) (cited by $18 \%$ of the articles) and Martin $(2000 ; 2012)$ (cited by $12 \%)$. The 
dominance of these theorists cohere with the findings of other reviews (e.g. Heyd-Metzuyanim et al. 2016).

In terms of methods used, none of the reviews systematically coded and counted the methods of identity studies. Darragh (2016) notes simply that the majority of articles use qualitative methods (which is consistent with other aforementioned reviews). She did provide some basic statistics on sample sizes of studies on which the articles are based: 58\% had fewer than 10 participants and only $9 \%$ had more than 100 participants (5\% of articles did not specify). Darragh (2016) notes, however, that even while studies gather data on multiple participants, in the reporting of the data 'Many articles presented case studies from larger studies' (p. 23). In terms of teacher identity, Lutovac and Kaasila (2018a) stated that most of the studies they reviewed used interviews, autobiographies, narratives and observations. They argue that since several studies point to differences between selfreporting and observational data, greater emphasis should be placed on observations of practice. This connects with Radovic et al.'s (2018) review that noted that research on learner identity predominantly drew on identities as narratives $(36 \%)$ and thus on data collection through narratives.

\subsection{Key critiques of, and contributions to, identity research in mathematics education}

By far, the most prevalent critique of identity research has been the vagueness of the "identity" concept and the lack of clarity around its operationalization (see Sfard and Prusak, 2005 for one of the most cited of these critiques). Critiques of the use of "identity" as a concept are not particular to mathematics education. There have been several challenges to the way in which the term is being used across fields. Brubaker and Cooper (2000) provide one such widely cited and thoroughly considered critique. They explain that in the sixties of the last century the term identity "proved highly resonant' and quickly diffused 'across disciplinary and national boundaries establishing itself in the journalistic as well as the academic lexicon' (p. 3). They refer to "the 'identity' crisis in the social sciences" (p. 2) and explain it as "a crisis of overproduction and consequent devaluation of meaning" (p. 3).

We have argued that the concept (identity) is deployed to do a great deal of analytic work-much of it legitimate and important. "Identity," however, is ill suited to perform this work, for it is riddled with ambiguity, riven with contradictory meanings, and encumbered by reifying connotations. (p. 34).

Brubaker and Cooper (2000) argue that alternative analytical idioms, such as identification and categorization; self-understanding and social location, and commonality, connectedness, groupness would be preferable and would avoid the confusion. Critiques on the use of identity in the field of teacher education research have similarly raised concerns that cut across subject specific areas. For example, Beijaard, Meyer and Verloop (2004) noted in their review of teacher professional identity that there was little consensus on a working definition of identity and that it was often not defined at all. Furthermore, they noted that the literature tended to conflate the concepts of self and identity, and that more clarity was needed on the perspectives used.

Sfard and Prusak's (2005) work, as noted above, is widely cited in articles on mathematics identity. They firstly provided a thorough critique of identity theorists prominent in the field of mathematics education, noting in particular a lack of operationalized definition in their work. Secondly, they provided an operationalized definition of identities as significant, reified and endorsable stories about a person (i.e. the product of collective storytelling) that they argued provides an analytic tool for investigating learning. In relation to the former they noted:

In the current literature the use of the word identity is rarely preceded by any explanations. In the absence of a definition, the reader is led to believe that identity is one of those self-evident notions that, whether reflectively or instinctively, arise from one's firsthand, unmediated experience. The influential publications by Lave and by Wenger are representative in this respect. Although identity is one of these writers' pivotal ideas, no conceptual preparations precede sentences such as "Learning... implies becoming a different person [and] involves the construction of identity" (Lave \& Wenger, 1991, p. 53), or "The experience of identity in practice is a way of being in the world" (Wenger, 1998, p. 151). (Sfard and Prusak 2005, p. 15).

Further, Sfard and Prusak (2005) argued that Gee's (2000) work, which says that identity is being recognized as a certain 'kind of person' in a given context, and the work of Holland and colleagues, provide promising beginnings but still fall short of providing an operationalised definition. They then provide the following definition:

In concert with the vision of identifying as a discursive activity, we suggest that identities may be defined as collections of stories about persons or, more specifically, as those narratives about individuals that are reifying, endorsable, and significant. (p. 16).

Albeit incredibly influential in the field of mathematics education (bearing, at the time of writing, over 1600 citations in Google Scholar), Sfard and Prusak's (2005) article also raised debate and dialogue regarding the definition of identity as "narrative". This debate was most notable in Juzwik's (2006) response to the paper, and Sfard's (2006) reply to Juzwik. In a nutshell, Juzwik (2006) claimed that 
although Sfard and Prusak's (2005) definition of “identity as narrative" is useful, further consideration should be given to the concept of "narrative" itself. In addition, she cautioned that some "extra-discursive" activity, such as tone of voice, manner of dress and other para-linguistic signals may be missed in the definition of "identity as narrative". To this, Sfard (2006) responded by claiming that Juzwik was, in fact, falling victim to an "ontological collapse" when she was differentiating between "discursively constructed" and "extra-discursively" constructed aspects of identity. She added:

One can hardly be surprised that the ontological collapse - the confusion between discursive and extradiscursive, and in particular, between what merely affects discourses and what is actually a part of thempersists in spite of the history of protests almost as long as the objectifying discourses themselves. (p. 24).

In what has later evolved into the "commognitive framework" (Sfard 2008), Sfard insists that identities are narratives. Identities are not reflected or represented by narratives. There is nothing "there" underlying the "narrative" (or more generally, the discourse) which the narrative describes. Yet, from our own readings, it seems that despite the prevalence of the "identity-as-narrative" definition in mathematics identity literature, few authors have engaged deeply with the full ontological and epistemological "package" of assumptions that comes with Sfard and Prusak's (2005) theorizing of this concept. Later, we shall relate to this gap and build upon it for two points: one, the "ontological collapses" that we found in literature on identity, namely, the implicit unification of different types of identity narratives; and two, the neglect of many writers in the field to differentiate between (or take into account) various identity stories of different authors. These stories have been typified by Sfard and Prusak (2005) using the tripartite signal ${ }_{\mathrm{A}} \mathrm{B}_{\mathrm{C}}$ : A being the author, $\mathrm{B}$ - the Protagonist (learner/teacher talked about) and $\mathrm{C}$ - the audience (who the story is told to). Most authors, even while relying on the "identity-as-narrative" definition, focus on stories of the type Interviewee $_{\text {Interviewee }}$ Researcher $_{\text {and neglect }}$ to relate to (or differentiate between) other stories. Further, in our review we note that while many papers cite their work, very few papers used Sfard and Prusak's (2005) operationalization of identity as reified, significant and endorsable stories. In part, this may be a result of the vagueness of these qualifying characteristics of narratives. Thus, although further works by Sfard and colleagues (e.g. Heyd-Metzuyanim and Sfard 2012; Heyd-Metzuyanim 2015) offered operationalizations for the "reifying" aspect of narratives, only Heyd-Metzuyanim (2015) engaged with the challenges of qualifying a narrative as "significant". Thus, this gap may show that Sfard and Prusak's (2005) definition itself may have been insufficiently operational, an issue that has been taken up by some of the papers reviewed (e.g. OpplandCordell and Martin 2015) and in our current issue.

We now turn to summarizing key commonalities in the critiques of recent reviews in mathematics education with a view to setting the scene for analyzing whether, in more recent literature of the leading mathematics education journals, these critiques have been addressed.

The central critique of both Darragh's (2016) review of 188 articles on mathematics identity and Radovic et al.'s (2018) review of 69 articles on mathematics learner identity is that this body of work continues to lack clear definitions of identity and often lacks conceptual coherence, including at times using incompatible theories. Other reviews mentioned above reinforce this. For example, Langer-Osuna and Esmonde (2017) argue that researchers must more clearly communicate their theoretical frames and that better connection is needed between these frames and analytic methods used. They also call for further theorizing of the concept noting: "the development of mathematics-linked individual and membership identities both need to be further theorized and studied" (p. 66). They acknowledge however, that coordinating individual and membership identities is methodologically challenging and note the need for methodological advances in this respect. Lutovac and Kaasila similarly call for clearer methodological articulation in research on teacher identity (2018a; 2018c).

In terms of key absences in the literature, Heyd-Metzuyanim, Lutovac and Kaasila (2016) note that since the bodies of literature on student and teacher identity have developed independently (even while sharing similar theoretical backgrounds), there is an absence of research connecting these two. As Darragh (2016) indicates, only 2\% of the articles reviewed studied both teacher and learner identities though, even in these articles, the research may not have focused on the relationship between these. Lutovac and Kaasila (2018a), in their review of mathematics teacher identity, note that this body of work seldom draws on general education identity research, which they believe has much to offer. They argue that there is an absence of individual or psychological emphases and that research in mathematics teacher identity literature is neglecting the individual. While noting Darragh's (2016) caution of identity being a "catch all" term for affect, Lutovac and Kaasila (2018a) critique the lack of attention to affect in relation to mathematics teacher identities. They also suggest a need for greater emphasis on practice as they found most studies on teacher identity were small scale, relying on autobiographical/narrative interviews.

The reviews of Darragh (2016) and Langer-Osuna and Esmonde (2017), on identity research in mathematics education generally, identified various categories of research according to the perspectives or definitions of identity used. The former suggested five broad categories 
of definition: identity as participative, narrative, discursive, psychoanalytic or performative. The latter identified four theoretical approaches to the study of identity, namely: poststructural theory, positioning theory, narrative theory, and psychoanalytic theory. More recently, Radovic et al. (2018), focusing on mathematics learner identity research, identified five broad categories of research, namely identity as: individual attributes; narratives; a relationship with a specific practice; ways of acting; and identity as afforded and constrained by local practices. These reviews discuss linkages and overlaps between various broad theories, influential theorists (such as Wenger 1998; Holland et al. 1998), key literature (e.g. Sfard and Prusak 2005) and the definitions used. Radovic et al. (2018) further elaborate on the operationalization and preferred methodology of research in each of their five categories. So, for example, research in the category of identity as a relationship with a specific practice was noted to operationalize identities as a sense of belonging/membership and to prefer surveys and interviews for data gathering. Radovic et al. (2018) further provide three dimensions for their five categories along which research can be positioned. These three dimensions are: the social/subjective; the enacted/representational and the change/stability dimension. Through these they argue the theoretical overlap between particularly the first three of Darragh's five categories (participative, narrative and discursive) can be unpacked by considering how theoretical concepts are used and operationalized. They also claimed that such analysis is more effective when one keeps in mind 'the social/subjective, representational/enacted, and change/stability dimensions of MLIs' (p. 26). The authors provide the following example of how this contributes further clarity to Darragh's (2016) categorization:

As an example, ideas from Holland et al. (1998) were identified in studies that Darragh categorized as conceptualizing identities as participative, narrative, and positional. Using our dimensional model, it is possible to understand how Holland and colleagues' ideas are differently employed and operationalized in these three groups. (p. 33).

Radovic et al.'s (2018) categorization, paired with the identification of one's location along various dimensions within a category will potentially be helpful for researchers in providing conceptual clarity and coherence to their perspective on, and working definition of, identity used. Indeed, this intended contribution to the field is captured in the title of their review paper 'Towards conceptual coherence in the research on mathematics learner identity: a systematic review of the literature.' Since this review has only recently been published, the extent to which researchers will draw on this framework to better locate and specify their identity research remains to be seen.

\section{Current state of identity research in leading mathematics education research journals}

For the present "state of the art" review, we chose to focus our analysis on identity research over the past 5 years (i.e. 2014-2018) in mathematics education published in the top twenty mathematics education research journals as identified by Williams and Leetham (2017). Our rationale for this time period was firstly that Darragh (2016), who provides the only comprehensive review of both learner and teacher identity, ended her review at 2014 (acknowledging that due to the time lag in publication not all 2014 articles were included). Radovic et al.'s (2018) review became available while we were writing this review and thus some overlap between our data set and that of Radovic et al. is inevitable. Their review however only includes articles, focused on learner identity, up to 2015, and again did not capture all 2015 articles in leading mathematics education journals.

Secondly, since we were aiming at a "state of the art" indicating where we are now in terms of research, we did not require extensive breadth for our review. Rather we aimed at conducting an in-depth analysis of all articles considered by the community of mathematics educators to be of sufficient quality to be published in one of the top twenty peer reviewed mathematics education research journals. This search period furthermore allowed us to include recently published reviews of the field of mathematics identity research all of which have been published from 2016 onwards. This enabled us to examine the critiques and points raised by the former reviews against the current trends.

The focus of our review was guided by a range of research questions, some necessitating descriptive statistics, others requiring deeper qualitative analysis of the current field as portrayed in mathematics education research journals. The research questions relating to descriptive statistics were: What is the distribution of articles across the time period, regions where research occurred and journals published in? Who is the focus of the research? What theoretical perspectives were used? What methods were used? What sample size was drawn on for the study and in the reporting of the study? What is the balance between empirical/theoretical research over the past 5 years? The research questions aimed at deeper qualitative analysis of the current field were: Are we moving past the key critiques? What new directions/issues/perspectives are emerging? In relation to issues of conceptual coherence, 
are there ontological collapses? Is identity central or peripheral to the paper? Is mathematics central or peripheral to the paper? Is engagement with mathematics central or peripheral to the paper? What is identity being used for? What is being advocated? For each question we reflect on whether our findings point to a continuation of, or shift in, earlier findings.

\subsection{Method of analysis}

As argued above, we included in our review all research papers published (2014-2018) on the topic of identity in the leading 20 mathematics education research journals (Williams and Leetham 2017, p. 337 ordered in relation to total citations), namely: Educational Studies in Mathematics (ESM); Journal for Research in Mathematics Education (JRME); Journal of Mathematical Behavior (JMB); For the Learning of Mathematics (FLM); Mathematical Thinking and Learning (MTL); Journal of Mathematics Teacher Education (JMTE); ZDM Mathematics Education (ZDM); Mathematics Education Research Journal (MERJ); International Journal of Math Education in Science and Technology (IJMEST); School Science and Mathematics (SSM); International Journal of Science and Mathematics Education (IJSME); Investigations in Mathematics Learning (IML; formerly FOCUS on Learning Problems in Mathematics); Teaching Mathematics and Its Applications (TMA); The Mathematics Educator (TME); Research in Mathematics Education (RME); International Journal for Technology in Mathematics Education (IJTME); Journal of Computers in Mathematics and Science Teaching (JCMST); Canadian Journal of Science, Mathematics and Technology Education (CJSMTE); PRIMUS (Problems, Resources, Issues in Undergraduate Mathematics Studies), and The Montana Mathematics Enthusiast (TMME).

The methodology of the review was guided by the Preferred Reporting Items for Systematic Reviews and MetaAnalyses (PRISMA) (Moher, Liberati, Tetzlaff, Altman, PRISMA Group 2009). EBSCOhost was used to do a journal-specific search in the databases Academic Search Premier and ERIC with the word identi* in the fields: title OR abstract OR keyword identifying OR subject descriptors, for each of the journal included. To triangulate, the search was run through SCOPUS for each of the 15 journals that were indexed there. As the most recent articles are often not yet indexed on databases, each of the 2018 issues of the twenty journals was hand-searched on their homepages. The first round of search was performed during August 2018. The last round was performed during the 2nd week of October 2018.

The results obtained were initially screened for whether the words containing the root identi* made reference to identity-for example that they did not refer to the "identification" of something or to an identity property, function or relation. Articles that did not refer in any sense to mathematical identity (such as those that only referred to science or engineering identity) were also excluded. A few papers that had identity in the abstract were later removed from the list as thorough reading of the paper clearly indicated that the paper was not about identity, had little mention of it and did not engage with it. All papers were copied into separate journal folders and a spreadsheet was created which provided summary information of each paper (such as authors, title, abstract, keywords, date) and information related to our descriptive research questions (such as where the research took place, perspectives and methods used, etc.) and our deeper analytic questions (such as How is identity defined and operationalized?).

Following some joint reading and analysis of eight papers in relation to our research questions and spreadsheet, some adaptations were made to the spreadsheet. We then proceeded to share the remaining papers between us and analyze them separately by responding to our research questions in the spreadsheet. A few papers were removed by agreement if on in-depth reading it was not seen to be about identity. This process resulted in 47 selected papers.

\subsection{Results}

\subsubsection{Descriptive statistics}

The field is seemingly still growing as while only six of the 47 articles were published in 2014, in 2018, by October when our final search occurred, there were already 13 articles available. The vast majority of articles were empirical (37). As discussed above, there were two large systematic reviews and one summary of 40 articles on mathematics teacher identity. There were also two commentaries (both by Langer-Osuna 2017; Langer-Osuna 2018) and four theoretical papers (the latter sometimes drew on empirical data from earlier research studies in the field). The small number of theoretical articles is similar to Darragh's (2016) finding of only $13 \%$ theoretical articles.

Similar to Darragh's findings, the regional distribution of our empirical articles, in terms of the country that research data was gathered in, is dominated by Northern America (12) (10 from USA and 2 from Canada); UK (6); and Europe (6) with South America (Chile/Argentina) (2) South Africa (4); Australia and New Zealand (2) and Israel (2) also contributing. A single article based on research conducted in each of Japan and Turkey points to the possibility of these new geographical areas entering the field. One empirical article focused on analyzing youth fiction that was not particular to a country (Darragh 2018). Only one empirical study included data from across two countries, Finland and Slovenia (Lutovac and Kaasila 2014). Since earlier reviews do not mention studies working 
across different countries it is difficult to say whether such across country research is new to the field. We believe research that includes data from different contexts, countries and regions could strengthen the field. Our data confirm that research on mathematics identity continues to be regionally clustered rather than being a global area of research, though the articles from Japan and Turkey indicate some engagement in new locations.

As with Darragh's finding the dominant mathematics education journals publishing identity research over the past 5 years are ESM (17), JRME (6) and JMTE (5). While Darragh's review notes significant contributions also from RME and FLM, in our review period these contribute only two and one article respectively. MERJ, however, which did not feature earlier as one of the leading contributing journals, contributed six articles-though five of these were in the 2015 special issue on the topic. This, as far as we know, was the first special issue on the topic. The remaining ten of the 47 articles were published in IJSME (1); IML (1); JMB (1); TMA (2); TME (1); TMME (1) and ZDM (3).

\section{Objects of the research}

Like Darragh, who found that slightly more research was focused on learners $(50 \%)$ than teachers $(45 \%)$, our review shows a leaning of empirical research towards learners (54\%) over teachers (32\%). While not all articles indicate the level of learners, where an indication was given there seemed to be an almost even distribution across elementary, primary, middle school, secondary and tertiary (college or university) learners. A small number of studies followed learners through their transition from one phase to the next (e.g. Darragh 2015). Of the articles focused on teachers there was almost an even split between pre-service and in-service teachers including novice teachers and out of field teachers of numeracy. One study looked at a teacher transitioning from pre-service to beginning teaching (Losano, Fiorentini and Villarreal 2018). As in the case of learners, there was an almost even spread across levels of primary and secondary, pre- and in-service teachers where stated. Single articles also focused on the identities of: adults (linked to data gathered when they were students) (Boaler and Selling 2017); immigrant parents (Takeuchi 2018), a railway worker (Wake 2014), a mathematician (Solomon, Radovic and Black 2016), and a researcher/teacher educator (using autoethnography, Knapp 2017). Of interest, one paper focused on portrayals of mathematics learners and teachers in novels (Darragh 2018), another on text analysis of a university mathematics course (le Roux and Adler 2016) and another on advertising images (Evans, Tsatsaroni and Czarnecka 2014). These articles point to the relevance of looking at data beyond teachers, learners and the teaching context. Interestingly, our review found no article focusing on both teacher and learner identities, though in some cases learner identities were analysed in relation to data gathered from teacher interviews, teacher practices or written stories about learners (e.g. Heyd-Metzuyanim and Graven 2016).

Methods and sample size

Almost all empirical studies focused on qualitative methods with only two studies drawing heavily on quantitative methods (i.e. Boaler and Selling 2017; Kasperson, Pepin and Sikko 2017, focusing in their studies on 21 and 185 learners respectively). All other learner articles focused on 8 or less learners (with two and four learners being the most common number of participants reported on). While many articles drew on data from much larger studies, the data reported on in the paper focused on a small selection from the larger sample of participants. Similarly, the sample sizes of the studies focused on teachers were small, ranging from 1 to 8 teachers. A quarter of the studies focused on a single teacher. This concurs with Darragh's (2016) finding that most of the studies had a sample of less than ten participants.

While several empirical papers mention having gathered a broad range of data (e.g. observational/video recorded, field note, interview, documentary data) the data included and reported on in each paper is generally a selection of those data sources. The data predominantly used and reported on in articles is interview data (76\%). While many papers supplement their interview data with another source of data gathered, particularly observational data, just under a third (32\%) of the articles focused almost exclusively on interview data. Observational data or video recording transcripts was the next most reported data source (35\%). Surveys, questionnaires (11\%) and fieldnotes (or journal entries) (14\%) were used in some articles though mostly to provide background data on participants or activities. Learner generated artefacts such as writings or drawings were also used in a few articles $(11 \%)$ while a movie that students produced was used in a single article (Pickard-Smith 2018). Another study used interview data with written autobiographies that included drawings and written reflections of pre-service teachers (Chen 2017).

\subsubsection{Themes and issues identified through our qualitative analysis}

\section{- Theoretical frameworks}

Similar to previous reviews, we found almost all papers relied on some form of socio-cultural frame. Since many of the works drew on multiple frameworks (though several did not identify them as "frameworks" but simply cited central works) it was hard to differentiate between sub-strands of socio-cultural theory. Still, similar to previous reviews, Holland et al. (1998), Sfard and Prusak (2005) and Lave and Wenger (1991)/Wenger (1998) figure prominently in 
the theoretical backgrounds of the papers reviewed. Some notable additional frameworks for conceptualizing identity were based on Cultural Historical Activity Theory (Jooganah and Williams 2016; Kaspersen, Pepin, and Sikko 2017), Archer's Social Realism (Westaway and Graven 2019), Positioning Theory (Darragh 2018), Bakhtin's theory of dialogism (Braathe and Solomon 2015) and Ricoeur's (1991) social theory (Lutovac and Kaasila 2018b). Although previous reviews found some works in the field relying on psychoanalytical frameworks, we found no such work in our review. In fact, it seems in the division between the "Eriksonian" identity and "Meadian" identity pointed to by Darragh (2016), the field has chosen the "Median" identity with such a consensus that we wonder whether this movement is not leaving some potentially fruitful paths behind. For example, we found hardly any reliance on the writings of Erikson, Freud and their successors in the field of psychology, on the development of self and identity. Some exceptions could be found in Hall, Towers and Martin (2018), who drew, in part, on Markus and Oyserman's (prominent researchers in social psychology) concepts of possible selves and self-concept. Yet these authors too, complemented their theoretical background by citing socio-cultural theories. Thus, none of the reviewed papers relied solely on psychological or psychoanalytical theory.

\section{- Definitions and operationalization of identity}

In relation to the main critique raised by earlier reviews and commentaries, regarding the definition of identity, we see a similar picture namely that most papers either do not define the concept, or define it only partially. However, our review may add some nuances to this general observation. First, it seems that the main gap lies not in the act of definition itself. Thus, many articles we reviewed included explicit statements such as "we define identity as..." or "we conceive of identity as ...". In addition, many papers allocate some significant portion of their theoretical background to review previously suggested definitions. In that sense, there seems to be awareness in the field of the importance of defining identity.

The weakness, instead, often lies in the operationalization of identity, namely, in stating precisely what identity is (for the researchers) and how it can be empirically studied. Some researchers choose to avoid the complexities of defining identity by focusing on an aspect (or sub-concept) that is more operationalizable, in their framework. For example, "positional identities" have been used by some (Foyn, Solomon and Braathe 2018; Langer-Osuna, 2015; Takeuchi, 2018), mostly based on Holland et al.'s (1998) framework. In these works, "positional identities" are mostly related to concepts of power and roles. For example, Foyn et al. (2018) define positional identities as "different roles which define who they (students) are in relation to each other" (p. 81). Others define the concepts related to identity well, but leave what "identity" itself is vague and undefined. And some do define identity, yet the definition is so broad that it is difficult to pinpoint the operationalization of all its subparts. For example, Boaler and Selling (2017) define identity as "a set of ideas, beliefs, and behaviors that may be performed in specific domains, such as the learning of mathematics". They claim that "Mathematical identity involves the ways in which students think about themselves in relation to mathematics and the extent to which they have developed a commitment to, are engaged in, and see value in mathematics and in themselves as learners of mathematics" (p. 82). This definition includes "ideas", "beliefs", "ways in which the students think about themselves", "commitment", "engagement and "seeing values"-all of which are difficult concepts to operationalize. A few papers provided operationalized definitions of identity by drawing on "identity as narrative" and in particular Sfard and Prusak (2005) (Andersson, Valero and Meaney 2015; Heyd-Metzuyanim 2017; Heyd-Metzuyanim and Graven 2016; Heyd-Metzuyanim, Tabach and Nachlieli 2016; Larnell 2016). Lutovac and Kaasila (2018b) rely on the definition of "identity as narrative" taken from other sources (Ricoeur 1991). Some, such as Oppland-Cordell and Martin (2015), relied on Wenger's (1998) theorizing of identity, not defining the term "identity" itself, but rather defining the concepts related to identity according to his theory, namely engagement, imagination and alignment.

Regardless of definition, an overwhelming majority of studies operationalize identity, at least in part, based on participants' narratives. The differences lie between those that only rely on narratives, and those that attempt to incorporate also "participative" aspects, mostly operationalized in the form of researchers' observations of the participants, or stories about the participants told by other significant narrators (such as parents or teachers). An interesting example for a study that used an unusual assortment of "voices" (or stories) about students is Radovic, Black, Salas, and Williams (2017). This study examined the construction of positive mathematical identities in the case of three girls. The uniqueness of the study stemmed from the fact that a full classroom was interviewed regarding each other, including social status and groupings, as well as students' identifications of each other in terms of mathematical ability. Some studies, such as Darragh (2015), explicitly distance themselves from the "narrative" definition of identity, claiming to adopt, a "participative" identity instead. They state: "We become a mathematics learner in a performative manner, and it is the repetition of 'performances' in mathematics learning contexts that generates our recognition of ourselves in certain ways as learners of mathematics." (p. 85). However, in this work, as in others that use the identity as 
"performance" or identity as forms of participation, what such "performance" is, and especially how it is assessed, is not clearly defined. Is it what the researcher recognizes in the interviewee's actions? Is it what the author believes that the learner/teacher thinks himself to be "performing"? Interestingly, it is precisely with this vagueness that Sfard and Prusak's (2005) delineation of 1st Person (1st P) stories from 3rd Person (3rd P) stories, could be of help. In particular, "performances" are usually, at least in effect, the researcher's 3rd P stories about the participants, based on his/her observations and analysis. Yet researchers aligning with the performative/participationist stance usually do not build on Sfard and Prusak's (2005) work, likely due to the association with the identity as narrative rather than participative perspective.

- Where are the mathematical objects?

Generally, the vast majority of the papers either backgrounded mathematics or dealt with it very tangentially. Very few (around 9) papers included specific examples of mathematical tasks or discussed mathematical content. In most of the studies, both those dealing with student identities and teacher identities, mathematics was talked about as a school discipline which students/teachers relate to, talk about or are observed in, but the mathematical content with which students/teachers were engaged was rarely presented or explored. In the cases where mathematics was foregrounded, it was mostly split from the discussion of identity or identity was tangential to the focus of the study. For example, Takeuchi (2018) discusses multiplication algorithms children of immigrant parents use, and parents' involvement in the learning of these algorithms. However, the concept of identity is relatively tangential in this study, and the analysis of positional identities is not directly related to the multiplication algorithms. Some exceptions to the split between identity and mathematical content could be found in works by Heyd-Metzuyanim (2017) and Heyd-Metzuyanim and Graven (2016) who analyze identifying and mathematizing processes concomitantly. These studies rely on the commognitive framework (Sfard 2008) to analyze identity construction processes as they happen in the classroom, while also foregrounding the mathematical routines followed by students.

- Ontological collapses-implicit unification of different types of identity narratives

Studies that adopted a discursive viewpoint usually did not have ontological collapses. They were very careful to report about participants' narratives and did not make claims about anything else. In contrast, studies that used "identity" as an eclectic ("catch-all") term for affect often had occurrences of ontological collapses. These could be seen in two forms: collapsing between what participants reported (their narratives) and their subjective experiences (feelings, beliefs etc.) and collapses between 1st P stories (told by the participant) and 3rd P stories (told about the participant by the researcher). Studies that relied on various sources of information regarding participants (interviews, observations, ethnographic data) were especially prone to the second type of collapse. Thus, often, researchers did not differentiate between the identity they had authored about the participant based on their observations, and the identity the participant authored in his/her interviews.

- What studies on identity are saying and what identity is used for

Our question What is the main storyline? was probably the most difficult to answer succinctly, since studies varied considerably in goals, questions asked and "bottom-line" answers. Also, since most studies were qualitative and based on very small samples, they rarely made generalized conclusions. Still, we were able to identify the following goals and functions for using the concept of identity underlying the studies we reviewed:

1. Making a socio-political claim. Studies such as these were often designed to examine issues of racial inequities (McGee 2015; Larnell 2016; Oppland-Cordell and Martin 2015), gender inequities (Foyn et al. 2018; Radovic et al. 2017; Solomon, Radovic and Black 2016), the need to change ways of working with students with disabilities (Goldstein 2018; Lambert 2015) or students from disadvantaged backgrounds (Heyd-Metzuyanim and Graven 2016; le Roux and Adler 2016; Takeuchi 2018). This is often a topic of studies of learner identities.

2. Providing a relatively holistic lens to examine learners' experiences in relation to their social context. Such studies (Black and Hernandez-Martinez 2016; Braathe and Solomon 2015; Darragh 2015; Heyd-Metzuyanim 2017; Kaspersen et al. 2017; Langer-Osuna 2018) usually put identity at the focus of their examination. Their goal is to illuminate how identity as a concept serves as a lens for examining students' experiences in the mathematics classroom as multi-faceted, multi-voiced, and impacted by various factors inside and outside of the classroom.

3. In studies focusing on teachers' identities, identity is used to examine teachers' experiences in various stages of their career (Hodges and Hodge 2017; Knapp 2017), including pre-service and in-service teachers' change and growth (Akkoç, Yeşildere-Imre and Balkanlioğlu 2014; Losano, Fiorentini and Villar- 
real 2017; Lutovac and Kaasila 2014, 2018b; Skog and Andersson 2015; van Putten, Stols, and Howie 2014), teachers' reactions to reform (Westaway and Graven 2019), the meaning (and support) of certain teaching practices such as teaching for numeracy skills (Bennison 2015) and teaching-learning interactions in the context of pre-service education (Heyd-Metzuyanim et al. 2016)

4. To make pedagogical claims. Most of these claims relate to providing students with richer and more diverse opportunities to engage with mathematics than are common in 'traditional' classrooms (Andersson et al. 2015; Boaler and Selling 2017; Langer-Osuna 2015; PickardSmith 2018; Wake 2014) as well as non-traditional assessment practices (Heritage and Wylie 2018). Some others argue for giving more attention to certain stages of transition in students' mathematical lives such as from high-school to university (Jooganah and Williams 2016).

\subsection{Discussion}

Our analysis reveals that, in general, the field is slowly moving towards more conceptual coherence in several aspects. First, there is unanimous reliance on social ("Meadian") views of identity rather than on psychological ones. We note that although this may be a sign of maturation and stabilization of the field, some important insights from the field of psychology may be left unnoticed. Thus, there seems to be a widening gap between studies of affect (beliefs, selfconcept etc.) and studies of identity (see also Heyd-Metzuyanim 2017). This gap seems to be wider in studies of learners' identities, which rarely build on literature from the field of affect (beliefs, emotions and attitudes) in comparison to studies of teachers' identity, which still often connect to studies on teachers' beliefs.

A second indicator of maturation of the field in terms of conceptual coherence can be seen in the growing number of studies that are quite explicit about their definition of identity. We note, however, that explicit definitions are not always operational. In relation to this gap, the participative/ performative types of definitions seem to be particularly challenging to operationalize. In our analysis, we have used Sfard and Prusak's (2005) definition of identity not as "the" ultimate definition, but rather as a lens through which other definitions can be examined. This examination has revealed that although most perspectives view the audience of identity-authoring as critical, many of the studies, including those that align with participative/performative conceptualizations, rely mostly on interviews. Thus, we found insufficient reflection on how identity or identity-work would be different if interview questions were asked by others (not researchers) or simply raised in discussion in a different context-such as with families of the interviewees or with their other teachers. If reflecting on one's mathematics learning or teaching involves identity work, then understanding how this occurs differently in settings other than researcher-interviewee would be critically important as the importance of audience implies we are getting a very one-dimensional set of data of teacher/learner identity work as a result of the present focus on interviews. With relation to this possible skew, we also note the necessity of raising awareness of ontological collapses, to which participative/action-based definitions seem particularly prone. If identity is to be assessed by multiple observations, authors and in different situations, there could be an understandable inclination for the researcher to collapse the various authored stories into one "identity" as participative/performative definitions invite. Yet such collapses often hide major parts of the stories-collection as they are limited to Interviewee Interviewee $_{\text {Researcher }}$ stories.

Our highlighting of ontological collapses also relates to the concern, expressed by some in the field of mathematics education, of "essentializing" identity. For example, Jurdak and colleagues (Jurdak, Vithal, de Freitas, et al. 2016), state that "Without intending to do so, some research on identity in mathematics education seems to re-entrench stereotypes about what sorts of identities excel at mathematics." (p. 15). Such essentializing - meaning the objectification of identity into a mental stable entity that has a causal effect on behavior, often goes hand in hand with ontological collapses that hide the fluid, dynamic and situated nature of identity. Notably, some researchers have attempted to avoid this objectification of identity with terms relating to the process of identifying or identification (e.g. Heyd-Metzuyanim and Sfard 2012) rather than to identity as an object. However, this attempt does not seem to have been taken up by many, perhaps because the field defines itself according to the word "identity" (as can be seen, for example, in the key-words used for most reviews on the subject). Other attempts for "processualizing" the talk on identity have leaned on the term "positioning", which is usually used as a verb and indicates a process (Bishop 2012; Wood 2013). Yet rarely have the links between the acts of "positioning" and the formation of an "identity" been clearly defined. This is something which Gresalfi and Hand (2019), as well as Andersson and Wagner (2019) take up in this issue.

\section{Contributions of the present special issue}

In this special issue we have identified different types of contributions that advance the field and address many of the issues raised in earlier critiques of identity work in the discussion above. These contributions involve: (1) new areas or foci of research (2) bringing new perspectives to mathematics identity research and (3) novel methodologies.

(i) New research areas of focus 
As pointed to by Radovic et al. (2018), research on young students' identities has been relatively rare. Black, Choudry, Pickard-Smith and Williams (2019) take a step forward in this direction by focusing on the emotion-cognition dialectic in the identity formation of a 6 year old boy. Black and her colleagues focus in particular on the emotion-cognition of surprise-astonishment that was expressed by the boy during a play activity where the children played 'as if' they were sellers and buyers in a 'Pizza shop'. Later, the research and child watched together a video of this play activity, which elicited surprise and laughter from the boy, and identifications of 'being clever'. This contrasted with his experience of feeling 'tired' during classroom mathematics. This study highlights the role of the emotion-cognition experience in acts of identification in joint activity between the child and the adult. Black et al. (2019) suggest that young children's emotional experiences in the early primary phase, which they equate with the Vygotskian concept of 'perezhivanie', may be key for the development of more crystalized narrative identities developed later on in life.

Another work that stretches the realm of identity to corporeal aspects is that of Gholson and Martin (2019). This study connects between the micro-interactions seen on video between a Black girl and a White female assistant teacher, and connects these micro-interactions to the wider racial narratives in the US that "press" upon the Black girl and form a painful experience for her in the mathematics classroom. This work relies on Butler's (1988) theorizing of gender as performance, connecting it with studies of Black students' cool pose as a protective coping mechanism that enables negotiating race, class and gender in urban settings. Gholson and Martin stretch the notion of performance and relational labor to the realm of phenomenological experience. They use their own positioning in the US society as means for understanding the black girl's "cool pose", her interpretations of the classroom situation and its connections to the physical pain ("head aches") she feels when doing mathematics.

The work of Goos and Bennison (2018) in the Australian context focuses on analyzing the identity formation of mathematics teacher educators (those contributing to the preparation of future teachers of mathematics) - both mathematicians and mathematics educators. They built on their earlier work, which brought a zone theory perspective to analyzing identity formation in mathematics education-of pre and in-service teachers, including out of field teachers teaching numeracy. In this paper, however, they focus on the identities of mathematics teacher educators, shedding light on this under-researched area as mathematics identity research has in the past focused either on teachers or learners or in some cases parents or mathematicians-but seldom the identities of those educating future teachers. Their analysis foregrounds the way in which teacher educators navigate productive tensions and drawing on zone theory contribute a theory of goal-directed change that is useful for understanding identity development and the role of individual agency within socio-cultural contexts. This theoretical advancement is useful for the field of mathematics identity more broadly than simply for mathematics teacher educators, which connects their contribution with (ii) below.

(ii) New theoretical perspectives shedding light on mathematics identity

Ntow and Adler (2019) bring afresh to the field Nasir and Cooks (2009) notions of practice-linked identities and identity resources (ideational, material and relational) to explore how mathematics teaching identities developed in relation to the resources offered in a particular Professional Development (PD) in South Africa. Their use of this work from out-of-field is original and novel, and so is their explicit focus on linking developing mathematics teacher identities (MTIs) with resources offered in PD. The use of Nasir and Cooks (2009) ideational, material and relational resources not only provides a language of description for the what of the PD the teachers participated in, but also provides new insights into how ideational resources influence individual mathematics teacher identities (MTIs), showing both similarities and differences. They further argue that the insights into the interrelationship between the what and how of the PD and developing MTIs does not sufficiently explain differences in MTIs - for this they include teacher motivations for PD participation that enables exploration of links between teacher learning and their practice-linked identities.

Grootenboer and Edwards-Groves (2018), similarly to Ntow and Adler (2019), argue for a practice perspective on mathematics identity though with the emphasis on the interconnections between how developing a mathematics identity is bound up with experiences of the sayings, doings and relatings in the mathematics classroom. Drawing on the work of Kemmis et al. (2014), where learning is defined as a process of being stirred into practices, they illuminate, through transcript analysis of 'a regular everyday-type' Australian lesson, the way in which learner's identities are formed through being stirred into these practices. Their analysis highlights that "one with a mathematical identity is someone who is stirred into the substantive mathematics practices (what is being learned) and learning practices of mathematics (how it is being learned)" (this issue).

Another novel theoretical approach to mathematical identity can be found in the study by Fellus (2019). Fellus builds on Ivanič (1998) networked identity model which differentiates between four types of identity: Authorial, Autobiographical, Discoursal and Socioculturally available identities. This framework is exemplified by Fellus through a review of 35 papers on mathematics learners' identity. Fellus derives from these studies central insights gained in the past decades of study on each one of these identity types. 
She argues that "Each of the four identity-related dimensions needs to be recognized as part of a larger system that has the potential to allow researchers as well as practitioners to have a view of the creases, wrinkles, and folds of the landscape we call identity" (this issue).

Starting with the claim that research in the field of identity "lacks a framework theoretically and methodologically to address the political dimension" (this issue), Chronaki and Kollosche (2019) suggest Laclau and Mouffe's discourse theory as a basis for extending the study of identity to the socio-political field. The basic concepts used from Laclau and Mouffe's theory are "nodal points" (moments that occupy central positions in a discourse) and "floating signifiers" (nodes which remain particularly open to different ascriptions of meaning). These are supplemented by the ideas of "hegemony" and "discursive struggle". Using these concepts, Chronaki and Kollosche analyze one interview with a 15 year old German girl named Anja. The suggested theoretical framework enables the authors to show how Anja's relation with mathematics can be understood as a struggle between the "proper mathematics" that retains hegemony and is described as "pointless", involving "remaining still and listening" and being "humiliated at the blackboard", and Anja's identity work which identifies her as a bodily active and a collaborative individual. Chronaki and Kollosche claim that such a discourse theory enables circumventing deficit discourses, allowing them "to avoid blaming either the students or the teacher by locating the divergent discourses from both sides in the wider discursive field" (this issue).

An additional novel theoretical framework for looking at identities - this time teachers' identities, is offered by Skott's (2018) Patterns of Participation (PoP). "PoP supplements the notions of practice and figured worlds from social practice theory, with the notion of self in Chicagoschool symbolic interactionism" (Skott 2018, this issue). Skott combines these concepts to "re-centre the individual" (ibid) while keeping a participatory stance towards the study of identity. The novel theoretical framework is exemplified on the case of Anna-a teacher who was followed by Skott for 4 years, since her graduation from preservice education. The data sources are wide in time and scale, including multiple interviews, observations, informal talks, numerous observations and even interviews with Anna's colleagues. From this vast database, Skott weaves a story about two different phases that Anna underwent during the 4 years: from being new in the Northgate school and identifying herself first and foremost as "a mathematics teacher" to being a "mathematics teacher at Northgate". The latter identification puts greater emphasis on her institutional affiliation and epitomizes other processes that Anna underwent such as working more collaboratively with her team while developing some professional distance from her students. Skott argues that PoP allows us to gain perspective on how "past and present practices and figured worlds function as generalised others" and that "The sense of agency in the notion of identity is then a matter of how Anna draws on and combines these generalized others,... when authoring an answer to the immediate situation" (this issue).

Another framework offered in this issue for looking at teachers' identity is that of social realism, put forward by Westaway (2019). Drawing on Archer's (2000) stratified view of persons as including sense of self, personal identity and social identity, Westaway (2019) focuses on reflexivity, which she defines as "the internal conversation individuals have about themselves and the situations they find themselves in". Westaway builds on Archer's differentiation between different modes of reflexivity-Communicative, Autonomous, Meta-reflexives, and Fractured reflexives to examine the emergence and expression of a Grade 3 mathematics teacher identity in South Africa. Her analysis of both interview data with the teacher (named Buhle) and observational data of Buhle's teaching practice, leads her to identify Buhle as shifting from being an "autonomous reflexive" in her early years, when she was self-reliant in her decision making and primarily concerned with upward mobility in the social order, to a "communicative reflexive" who reproduces the status quo, maintaining old teaching roles in the face of reform efforts. Like Skott (2018), Westaway (2019) claims to "reinsert the individual"- - this time, into the process of social morphogenesis and morphostasis. By that, she is challenging "the assumption that teachers are mere products of a social system" (this issue) and aims to highlight the role of teachers' agency in the reproduction of old systemic roles.

Gresalfi and Hand (2019) is another paper with a clear theoretical contribution, this time, weaving together different strands of literature that take a situative perspective to mathematics identity. Their proposed model connects Norms, Frames and Narratives as three different types of resources students draw on to develop their mathematical identity. The goal of this model, Gresalfi and Hand suggest, is to offer "a design heuristic" for educators who wish to develop certain identities in the classroom. They focus on two particular interventions: intervening by disrupting racial narratives, exemplified through the work of Gutstein (2016); and intervening through disrupting classroom norms and practices, exemplified by the work of Boaler (2008). Their proposed model affords detecting both coherence and incoherence in programs of intervention by examining how the different levels (narratives and norms) relate to each other and whether one level is neglected at the expense of the other.

(iii) Methodological contributions

Several of the papers mentioned above indeed also provide methodological contributions in terms of new analytical 
methods. Here we mention those papers whose contribution we identified as primarily methodological.

Lutovac and Kaasila (2018c) provide an original review of the methodological landscape of teacher identity research in mathematics education. Examining 52 studies published between 2000 and 2017 in peer reviewed scholarly journals they argue that the overwhelming dominance of qualitative approaches (with interviews, written reflections or narratives, and classroom observations) and limited analytic approaches is constraining what research is able to offer the field. They argue that future research on mathematicsrelated teacher identity should (1) consider mixed methods approaches that would support greater generalization of findings, (2) combine research on different groups of teachers (such as research into both pre- and in-service teachers or elementary and higher grade mathematics teachers) so as to facilitate the examination of the intersection of different groups of teacher identities and (3) be explicit in their writing about the methodological decisions they make (in particular, they call for the use of methodological labels).

While this special issue remains skewed towards qualitative methodologies, there are some particularly novel analytic approaches that disrupt the monotony of the landscape noted above. Darragh and Radovic's (2019b) study on Chilean primary mathematics teacher identities after PD, while following a classic thematic analysis of semistructured teacher interviews, introduces the innovative concept of teachers' collective identity performances. This concept is illuminated through their combining ten individual teacher narrative analyses into a movie synopsis of a fictional protagonist 'Tia'. Their analysis and presentation of the collective identity performances of the teachers highlight dissonance between what teachers perceived as attractive identities (e.g. mother-saviour) and what was promoted in the PD (e.g. allowing learners to struggle independently with problem solving). Their innovative method of combing the data of teachers and weaving it into a fictional movie script enabled breadth and depth that powerfully illuminate how teacher identities are culturally and contextually produced. This achievement turns attention to the importance of $\mathrm{PD}$, noting and responding to these cultural and educational contexts.

In the domain of learners' identity in action, Andersson and Wagner (2019) propose a novel methodology for examining students' positioning moves with relation to their language repertoires. They use an interaction among a group of grade 10 students who are engaged in a problem-solving situation to exemplify their conceptualization of identities as drawing on a "torus" of discourses that are available to a person. Within the available discourses, Andersson and Wagner identify several authority structures: Personal Authority, Discourse as Authority, Implicit Discursive Authority and Personal Latitude. Each one of these structures affords certain positions and certain available identities. Their illustrative example shows how positions and taking up certain identities can change when students turn to draw on outof-school discourses, such as the "hobby discourse". Specifically, it enabled a breakthrough in the group's problemsolving efforts by affording one of the students (who was previously positioned negatively in the friendship discourse) an opportunity to draw on his identity as a Rubik's Cube player. This move changed this student's positioning, and offered the possibility for others to listen to his solution and build upon it.

Another study, which attempts to re-construct identity from discursive actions, is Heyd-Metzuyanim and Shabtay (2019). This paper explores teacher identities in relation to their pedagogical discourse (their narratives about 'good' teaching) and how this links with broader pedagogical discourses available. They identify two key forms of pedagogical discourse, namely Exploration Pedagogical Discourse (EPD) and Acquisition Pedagogical Discourse (APD). These they link with Sfard and Lavie's (2005) commognitive distinction between ritual and explorative participation. EPD links with widely promoted mathematics education reform literature (and promoted in the official documentation provided to the teachers in their study by the Israeli ministry) and APD links with 'traditional' or teacher-centered instruction. Heyd-Metzuyanim and Shabtay's novel focus on researching individual teacher identity in relation to the construct of multiple pedagogical discourses available (official and unofficial) extends the fields' understanding and use of the notion of pedagogic identities. Their paper contributes a useful analytic frame for understanding individual teacher identities as the nexus of narratives adopted from different pedagogical discourses.

\section{Summary and implications for future directions}

From the review of literature prior to this Special Issue we are able to both note some continued absences in the field as well as absences that have been taken forward by the authors herein. We note several divisions calling for researchers' attention. For example, attention is needed to the gap between identity and mathematical objects. Unless identity is made relevant for actual learning processes in the mathematics classroom, and more particularly, in specific domains of mathematics (arithmetic, algebra, geometry etc.), it is likely that teachers will not pay much attention to it. This point echoes Jorgensen's (2014) critique of social theories of learning in general. Jorgensen argues that mathematics educators drawing on social theories and identity often render mathematics invisible. As a result, what is being advocated by these studies has made little progress in enabling greater 
access to mathematics of marginalized communities. She writes 'the social theory has failed to make any substantive inroads into challenging the status quo in terms of equity, access and/or success. It is almost as if mathematics has become quite secondary to any analysis." (p. 314). Jorgensen further argues that despite these theories significant contribution around the impact of context in a broader sense than mathematics, "such a position is limiting within this field. It could be applied to almost any field, and thus render the mathematics per se as silent." (p. 315). Three papers in this issue foreground mathematics-Heyd-Metzuyanim and Shabtay, Andersson and Wagner, and to some extent Gholson and Martin. It is notable that these studies are also those that foreground discourse and the extraction of identity from discursive actions. This highlights how important this building on discourse-action data is for bringing in the mathematics, and points to the productiveness of pushing forward methodologies that extract identity from classroom activity.

Another gap persists between learners' and teachers' identities, a gap noted already by Heyd-Metzuyanim, Lutovac, and Kaasila (2016) and repeatedly observed, even in conference practices such as dividing sub-groups of the upcoming ICME 14 into those relating to learners' identities and those relating to teachers' identities (http://www.icme1 4.org/). The study of learners and teachers' identities as they relate to each other is a curious absence, given the fact that most studies of identity rely on frameworks that see learning as becoming a participant in a certain community. It would seem probable that such a view would propel researchers to examine the central players in such a community (learners and teachers) concomitantly, yet such concomitant views are practically absent, at least in the studies we reviewed.

The contribution of papers in this special issue, we argue, has taken the field forward in terms of new and more elaborate ways of looking at identity from action, rather than (only) from self-reports. It also contributes new connections between identity and other concepts: positioning (Andersson and Wagner), emotion (Black et al.), framing and cultural narratives (Gresalfi and Hand). We hope that these contributions will assist also for questions looking at teachers and students' identities concomitantly. This, since the examination of classroom activity can provide a useful ground for studying how students and teachers enact their identities together.

Our review of the field showed continued dominance of specific theorists and theories in the field. A key contribution of this special issue is the proliferation of theories. We see this as a strength of this issue and an indication of the field growing. However, this proliferation can also bring challenges as has been noted in discussions of multiple theories in mathematics education in general (e.g. Radford 2008). The most pressing challenge would probably be, as noted also in our review above, the issue of definition of identity.
Fellus (2019) and Greslafi and Hand (2019) contributions in this volume, concerning the theorizing of identity from multiple viewpoints, offer ways forward for authors wishing to locate their work in the ever-growing supply of theories and methodologies for studying identity.

The field of identity research in mathematics education has become established and is continuing to grow and find new creative and innovative ways of understanding and explaining mathematics complex learning and teaching processes. We hope this Special Issue contributes to pushing the boundaries of this field theoretically, empirically and methodologically.

Acknowledgements This work is supported by the South African Research Chairs Initiative of the Department of Science and Technology and National Research Foundation (Grant no. 74658). We thank Pamela Vale for her assistance with the literature search.

Open Access This article is distributed under the terms of the Creative Commons Attribution 4.0 International License (http://creativeco mmons.org/licenses/by/4.0/), which permits unrestricted use, distribution, and reproduction in any medium, provided you give appropriate credit to the original author(s) and the source, provide a link to the Creative Commons license, and indicate if changes were made.

\section{References}

Akkoç, H., Yeşildere-Imre, S., \& Balkanlioğlu, M. A. (2014). Examining professional identity through story telling. Research in Mathematics Education, 16(2), 204-205. https://doi.org/10.1080/14794 802.2014.918340

Andersson, A., Valero, P., \& Meaney, T. (2015). "I am [not always] a maths hater": Shifting students' identity narratives in context. Educational Studies in Mathematics, 90(2), 143-161. https://doi. org/10.1007/s10649-015-9617-z.

Andersson, A., \& Wagner, D. (2019). Identities available in intertwined discourses: Mathematics student interaction. ZDM Mathematics Education. https://doi.org/10.1007/s11858-019-01036-w.

Archer, M. S. (2000). Being Human: The problem of agency. Cambridge: Cambridge University Press.

Beijaard, D., Meijer, P. C., \& Verloop, N. (2004). Reconsidering research on teachers' professional identity. Teaching and Teacher Education, 20, 107-128.

Bennison, A. (2015). Supporting teachers to embed numeracy across the curriculum: A sociocultural approach. ZDM International Journal on Mathematics Education, 47(4), 561-573. https://doi. org/10.1007/s11858-015-0706-3.

Bishop, J. (2012). "She's always been the smart one. I've always been the dumb one": Identities in the mathematics classroom. Journal for Research in Mathematics Education, 43(1), 34-74.

Black, L., Choudry, S., Pickard-Smith, K., \& Williams, J. (2019). Theorising the place of emotion-cognition in research on mathematical identities: The case of early years mathematics. ZDM Mathematics Education. https://doi.org/10.1007/s11858-018-01021-9.

Black, L., \& Hernandez-Martinez, P. (2016). Re-thinking science capital: The role of "capital" and "identity" in mediating students' engagement with mathematically demanding programmes at university. Teaching Mathematics and Its Applications, 35(3), 131-143. https://doi.org/10.1093/teamat/hrw016. 
Boaler, J. (2008). Promoting 'relational equity' and high mathematics achievement through an innovative mixed-ability approach. British Educational Research Journal, 34(2), 167-194.

Boaler, J., \& Greeno, J. (2000). Identity, agency, and knowing in mathematics worlds. In J. Boaler (Ed.), Multiple perspectives on mathematics education (pp. 171-200). Westport, CT: Ablex.

Boaler, J., \& Selling, S. K. (2017). Psychological imprisonment or intellectual freedom? A longitudinal study of contrasting school mathematics approaches and their impact on adults' lives. Journal for Research in Mathematics Education, 48(1), 78. https://doi. org/10.5951/jresematheduc.48.1.0078.

Braathe, H. J., \& Solomon, Y. (2015). Choosing mathematics: The narrative of the self as a site of agency. Educational Studies in Mathematics, 89, 151-166. https://doi.org/10.1007/s10649-014-9585-8.

Brubaker, R., \& Cooper, F. (2000). Beyond "identity". Theory and Society, 29, 1-47.

Butler, J. (1988). Performative acts and gender constitution: An essay in phenomenology and feminist theory. Theatre Journal, 40(4), 519-531. https://doi.org/10.2307/3207893.

Chen, R. J. (2017). Prospective elementary teachers' aesthetic experience and relationships to mathematics. Journal of Mathematics Teacher Education, 20(3), 207-230.

Chronaki, A., \& Kollosche, D. (2019). Refusing mathematics: A discourse theory approach on the politics of identity work. ZDM Mathematics Education. https://doi.org/10.1007/s11858-01901028-w.

Darragh, L. (2015). Recognising 'good at mathematics': Using a performative lens for identity. Mathematics Education Research Journal, 27(1), 83-102.

Darragh, L. (2016). Identity research in mathematics education. Educational Studies in Mathematics, 93(1), 19-33. https://doi. org/10.1007/s10649-016-9696-5.

Darragh, L., \& Radovic, D. (2019b). "To Tia with love": Chilean mathematics teacher identities after professional development. ZDM Mathematics Education. https://doi.org/10.1007/s11858-01801023-7.

Darragh, L., \& Radovic, D. (2019a). Mathematics learner identity. In S. Lerman (Ed.), Encyclopedia of mathematics education. Dordrecht: Springer. (in press).

Darragh, L. (2018). Loving and loathing: Portrayals of school mathematics in young adult fiction. Journal for Research in Mathematics Education, 49(2), 178-209. http://www.jstor.org.proxy.mul. missouri.edu/stable/10.5951/jresematheduc.49.2.0178.

Erikson, E. H. (1968). Identity, youth and crisis. New York: Norton.

Evans, J., Tsatsaroni, A., \& Czarnecka, B. (2014). Mathematical images in advertising: Constructing difference and shaping identity, in global consumer culture. Educational Studies in Mathematics, 85(1), 3-27. https://doi.org/10.1007/s10649-013-9496-0.

Fellus, O. O. (2019). Connecting the dots: Toward a networked framework to conceptualizing identity in mathematics education. ZDM Mathematics Education (in press).

Foyn, T., Solomon, Y., \& Braathe, H. J. (2018). Clever girls' stories: The girl they call a nerd. Educational Studies in Mathematics, 98(1), 77-93. https://doi.org/10.1007/s10649-017-9801-4.

Gee, J. P. (2000). Identity as an analytic lens for research in education. Review of Research in Education, 25, 99-125.

Gholson, M., \& Martin, D. B. (2019). Blackgirl face: Racialized and gendered performativity in mathematical contexts. ZDM Mathematics Education (in press).

Goldstein, D. S. (2018). Mathematics identities of competence in a middle-grades d/Deaf and hard-of-hearing classroom. Investigations in Mathematics Learning, 10(3), 145-158. https://doi. org/10.1080/19477503.2018.1467081.

Goos, M., \& Bennison, A. (2018). A zone theory approach to analysing identity formation in mathematics education. ZDM Mathematics Education. https://doi.org/10.1007/s11858-018-1011-8.
Graven, M., \& Lerman, S. (2014). Mathematics teacher identity. In S. Lerman (Ed.), Encyclopaedia of Mathematics Education (pp. 434-438). Dordrecht: Springer.

Graven, M., \& Lerman, S. (2019). Mathematics teacher identity. In S. Lerman (Ed.), Encyclopedia of Mathematics Education. Dordrecht: Springer. (in press).

Gresalfi, M., \& Hand, V. M. (2019). Coordinating situated identities in mathematics classrooms with sociohistorical narratives: A consideration for design. ZDM Mathematics Education. https://doi. org/10.1007/s11858-019-01034-y.

Grootenboer, P., \& Edwards-Groves, C. (2018). Learning mathematics as being stirred into mathematical practices: An alternative perspective on identity formation. ZDM Mathematics Education. https://doi.org/10.1007/s11858-018-01017-5.

Gutstein, E. (2016). "Our issues, our people-Math as our weapon": Critical mathematics in a Chicago neighborhood high school. Journal for Research in Mathematics Education, 47(5), 454-504.

Hall, J., Towers, J., \& Martin, L. C. (2018). Using I poems to illuminate the complexity of students' mathematical identities. Educational Studies in Mathematics, 99(2), 181-196. https://doi.org/10.1007/ s10649-018-9839-y.

Harré, R., \& van Langenhove, L. (1999). Positioning theory. Oxford: Blackwell.

Heritage, M., \& Wylie, C. (2018). Reaping the benefits of assessment for learning: Achievement, identity, and equity. ZDM Mathematics Education, 50(4), 729-741. https://doi.org/10.1007/s1185 8-018-0943-3.

Heyd-Metzuyanim, E. (2015). Vicious cycles of identifying and mathematizing - a case study of the development of mathematical failure. Journal of the Learning Sciences, 24(4), 504-549.

Heyd-Metzuyanim, E. (2017). Identity as a nexus of affect and discourse in mathematical learning. For the Learning of Mathematics, 37(3), 33-38.

Heyd-Metzuyanim, E., \& Graven, M. (2016). Between people-pleasing and mathematizing-South African learners' struggle for numeracy. Educational Studies in Mathematics, 91(3), 349-373.

Heyd-Metzuyanim, E., Lutovac, S., \& Kaasila, R. (2016a). Identity. In M. S. Hannula, G. A. Goldin, E. Heyd-Metzuyanim, A. Jansen, R. Kassila, S. Lutovac, P. Di Martino, F. Morselli, J. A. Middleton, M. Pantziara, \& Q. Zhang (Eds.), Attitudes, beliefs, motivation, and identity in mathematics education: An overview of the field and future directions. New York: Springer Open. https://doi. org/10.1007/978-3-319-32811-9_1.

Heyd-Metzuyanim, E., \& Sfard, A. (2012). Identity struggles in the mathematics classroom: On learning mathematics as an interplay of mathematizing and identifying. International Journal of Educational Research, 51-52, 128-145. https://doi.org/10.1016/j. ijer.2011.12.015.

Heyd-Metzuyanim, E., \& Shabtay, G. (2019). Narratives of 'good' instruction: Teachers' identities as drawing on exploration vs. acquisition pedagogical discourses. ZDM Mathematics Education. https://doi.org/10.1007/s11858-018-01019-3.

Heyd-Metzuyanim, E., Tabach, M., \& Nachlieli, T. (2016b). Opportunities for learning given to prospective mathematics teachers: Between ritual and explorative instruction. Journal of Mathematics Teacher Education, 19(6), 547-574. https://doi.org/10.1007/ s10857-015-9311-1.

Hodges, T. E., \& Hodge, L. L. (2017). Unpacking personal identities for teaching mathematics within the context of prospective teacher education. Journal of Mathematics Teacher Education, 20(2), 101-118. https://doi.org/10.1007/s10857-015-9339-2.

Holland, D., Lachicotte, W., Skinner, D., \& Cain, C. (1998). Identity and agency in cultural worlds. Cambridge: Harvard University Press.

Ivanič, R. (1998). Writing and Identity: The discoursal construction of identity in academic writing. Amsterdam: John Benjamins. 
Jooganah, K., \& Williams, J. S. (2016). Contradictions between and within school and university activity systems helping to explain students' difficulty with advanced mathematics. Teaching Mathematics and Its Applications, 35(3), 159-171. https://doi. org/10.1093/teamat/hrw014.

Jorgensen, R. (2014). Social Theories of Learning: A need for a new paradigm in mathematics education. In J. Anderson, M. Cavanagh, \& A. Prescott (Eds.), Curriculum in focus: Research guided practice (Proceedings of the 37th annual conference of the Mathematics Education Research Group of Australasia) (pp. 311-318). Sydney: MERGA.

Jurdak, M., Vithal, R., de Freitas, E., Gates, P., \& Kolloosche, D. (2016). Social and Political Dimensions of Mathematics Education-Current Thinking. ICME13, Springer Open.

Juzwik, M. (2006). Situating narrative-minded research: A commentary on Anna Sfard and Anna Prusak's “Telling Identities". Educational Researcher, 35(9), 13-21.

Kaspersen, E., Pepin, B., \& Sikko, S. A. (2017). Measuring STEM students' mathematical identities. Educational Studies in Mathematics, 95(2), 163-179. https://doi.org/10.1007/s10649-016-9742-3.

Kemmis, S., Wilkinson, J., Edwards-Groves, C., Hardy, I., \& Grootenboer, P., Bristol, L. (2014). Changing practices, changing education. Singapore: Springer.

Knapp, M. C. (2017). An autoethnography of a (reluctant) teacher leader. Journal of Mathematical Behavior, 46, 251-266. https:// doi.org/10.1016/j.jmathb.2017.02.004.

Lambert, R. (2015). Constructing and resisting disability in mathematics classrooms: A case study exploring the impact of different pedagogies. Educational Studies in Mathematics, 89(1), 1-18. https://doi.org/10.1007/s10649-014-9587-6.

Langer-Osuna, J. (2015). Linear equations and rap battles: How students in a wired classroom utilized the computer as a resource to coordinate personal and mathematical positional identities in hybrid spaces. Mathematics Education Research Journal, 27(1), 51-64. https://doi.org/10.1007/s13394-014-0125-8.

Langer-Osuna, J. M. (2018). Exploring the central role of student authority relations in collaborative mathematics. ZDM Mathematics Education. https://doi.org/10.1007/s11858-018-0965-x.

Langer-Osuna, J. M., \& Esmonde, I. (2017). Insights and advances on research on identity in mathematics education. In J. Cai (Ed.), Compendium for research in mathematics education (pp. 637 648). Reston, VA: National Council of Teachers of Mathematics.

Langer-Osuna, J. M. (2017). Authority, identity, and collaborative mathematics. Journal for Research in Mathematics Education, 48(3), 237-247.

Larnell, G. V. (2016). More than just skill: Examining mathematics identities, racialized narratives, and remediation among black undergraduates. Journal for Research in Mathematics Education, 47(3), 233-269. https://doi.org/10.5951/jresematheduc.47.3.0233.

Lave, J., \& Wenger, E. (1991). Situated learning: Legitimate peripheral participation. New York: Cambridge University Press.

Lerman, S. (2000). The social turn in mathematics education. In J. Boaler (Ed.), Multiple perspectives on mathematics education (pp. 19-44). Westport, CT: Ablex.

Losano, L., Fiorentini, D., \& Villarreal, M. E. (2017). The development of a mathematics teacher's professional identity during her first year teaching. Journal of Mathematics Teacher Education. https ://doi.org/10.1007/s10857-017-9364-4.

Losano, L., Fiorentini, D., \& Villarreal, M. (2018). The development of a mathematics teacher's professional identity during her first year teaching. Journal of Mathematics Teacher Education, 21(3), 287-315.

Lutovac, S., \& Kaasila, R. (2014). Pre-service teachers' future-oriented mathematical identity work. Educational Studies in Mathematics, 85(1), 129-142. https://doi.org/10.1007/s10649-013-9500-8.
Lutovac, S., \& Kaasila, R. (2017). Future Directions in Research on Mathematics-Related Teacher Identity. International Journal of Science and Mathematics Education. https://doi.org/10.1007/ s10763-017-9796-4.

Lutovac, S., \& Kaasila, R. (2018a). Future directions in research on mathematics-related teacher identity. International Journal of Science and Mathematics Education, 16(4), 759-776. https://doi. org/10.1007/s10763-017-9796-4.

Lutovac, S., \& Kaasila, R. (2018b). An elementary teacher's narrative identity work at two points in time two decades apart. Educational Studies in Mathematics, 98(3), 253-267. https://doi.org/10.1007/ s10649-018-9816-5.

Lutovac, S., \& Kaasila, R. (2018c). Methodological landscape in research on teacher identity in mathematics education: A review. ZDM Mathematics Education. https://doi.org/10.1007/s1185 8-018-1009-2.

Martin, D. (2000). Mathematics success and failure among AfricanAmerican youth. Mahwah: Lawrence Erlbaum Associates.

Martin, D. (2012). Learning mathematics while black. Educational Foundations, 26, 47-66.

McGee, E. O. (2015). Robust and fragile mathematical identities: A framework for exploring racialized experiences and high achievement among black college students. Journal for Research in Mathematics Education, 46(5), 599. https://doi.org/10.5951/jresemathe duc.46.5.0599.

Mead, G. J. (1934). Mind, self and society. Chicago: University of Chicago Press.

Moher, D., Liberati, A., Tetzlaff, J., Altman, D. G., \& The PRISMA Group. (2009). Preferred reporting items for systematic reviews and meta-analyses: The PRISMA statement. PLoS Med, 6(7), e1000097. https://doi.org/10.1371/journal.pmed1000097.

Nasir, N. S., \& Cooks, J. (2009). Becoming a hurdler: How learning settings afford identities. Anthropology \& Education Quarterly, 40(1), 41-61.

Ntow, F. D., \& Adler, J. (2019). Identity resources and mathematics teaching identity: An exploratory study. ZDM Mathematics Education. https://doi.org/10.1007/s11858-019-01025-z.

Oppland-Cordell, S., \& Martin, D. B. (2015). Identity, power, and shifting participation in a mathematics workshop: Latin@ students' negotiation of self and success. Mathematics Education Research Journal, 27(1), 21-49. https://doi.org/10.1007/s1339 4-014-0127-6.

Pickard-Smith, K. (2018). Disordering mathematical identity stories through dramatic filmed parody "Math Therapy". The Mathematics Enthusiast, 15(1), 251-277.

van Putten, S., Stols, G., \& Howie, S. (2014). Do prospective mathematics teachers teach who they say they are? Journal of Mathematics Teacher Education, 17(4), 369-392.

Radford, L. (2008). Connecting theories in mathematics education: challenges and possibilities. ZDM Mathematics Education 40(2), 317-327.

Radovic, D., Black, L., Salas, C. E., \& Williams, J. S. (2017). Being a girl mathematician: Diversity of positive mathematical identities in a secondary classroom. Journal for Research in Mathematics Education, 48(4), 434. https://doi.org/10.5951/jresemathe duc.48.4.0434.

Radovic, D., Black, L., Williams, J., \& Salas, C. E. (2018). Towards conceptual coherence in the research on mathematics learner identity: a systematic review of the literature. Educational Studies in Mathematics. https://doi.org/10.1007/s10649-018-9819-2.

Ricoeur, P. (1991). Narrative identity. Philosophy Today, 35(1), 73-81. https://doi.org/10.1007/s10857-015-9329-4.

le Roux, K., \& Adler, J. (2016). A critical discourse analysis of practical problems in a foundation mathematics course at a South African university. Educational Studies in Mathematics, 91(2), 227-246. https://doi.org/10.1007/s10649-015-9656-5. 
Sfard, A. (2006). Telling ideas by the company they keep: A response to the critique by Mary Juzwik. Educational Researcher, 35(9), $22-27$.

Sfard, A. (2008). Thinking as communicating. New York: Cambridge University Press.

Sfard, A., \& Prusak, A. (2005). Telling identities: In search of an analytic tool for investigating learning as a culturally shaped activity. Educational Researcher, 34(4), 14-22.

Skog, K., \& Andersson, A. (2015). Exploring positioning as an analytical tool for understanding becoming mathematics teachers' identities. Mathematics Education Research Journal, 27(1), 65-82. https://doi.org/10.1007/s13394-014-0124-9.

Skott, J. (2018). Changing experiences of being, becoming, and belonging: Teachers' professional identity revisited. ZDM Mathematics Education. https://doi.org/10.1007/s11858-018-1008-3.

Solomon, Y., Radovic, D., \& Black, L. (2016). "I can actually be very feminine here": Contradiction and hybridity in becoming a female mathematician. Educational Studies in Mathematics, 91(1), 55-71. https://doi.org/10.1007/s10649-015-9649-4.

Takeuchi, M. A. (2018). Power and identity in immigrant parents' involvement in early years mathematics learning. Educational Studies in Mathematics, 97(1), 39-53. https://doi.org/10.1007/ s10649-017-9781-4.

Wake, G. (2014). Making sense of and with mathematics: The interface between academic mathematics and mathematics in practice.
Educational Studies in Mathematics, 86(2), 271-290. https://doi. org/10.1007/s10649-014-9540-8.

Wenger, E. (1998). Communities of practice. Cambridge: Cambridge University Press.

Westaway, L. (2019). The role of reflexivity in the emergence and expression of teachers' identities in teaching primary school mathematics. ZDM Mathematics Education. https://doi.org/10.1007/ s11858-019-01042-y.

Westaway, L., \& Graven, M. (2019). Exploring grade 3 teachers' resistance to 'take up' progressive mathematics teaching roles. Math ematics Education Research Journal., 31(1), 27-46. https://doi. org/10.1007/s13394-018-0237-7.

Williams, S. R., \& Leatham, K. R. (2017). Journal quality in mathematics education. Journal for Research in Mathematics Education, 48(4), 369-396.

Wood, M. B. (2013). Mathematical micro-identities: Moment-tomoment positioning and learning in a fourth-grade classroom. Journal for Research in Mathematics Education, 44(5), 775-808. https://doi.org/10.5951/jresematheduc.44.5.0775.

Publisher's Note Springer Nature remains neutral with regard to jurisdictional claims in published maps and institutional affiliations. 